\title{
Surveillance of Physical Activity and Sedentary Behavior Among Youth and Adults in the United States: History and Opportunities
}

\author{
John D. Omura, Geoffrey P. Whitfield, Tiffany J. Chen, Eric T. Hyde, Emily N. Ussery, \\ Kathleen B. Watson, and Susan A. Carlson
}

\begin{abstract}
Background: Surveillance is a core function of public health, and approaches to national surveillance of physical activity and sedentary behavior have evolved over the past 2 decades. The purpose of this paper is to provide an overview of surveillance of physical activity and sedentary behavior in the United States over the past 2 decades, along with related challenges and emerging opportunities. Methods: The authors reviewed key national surveillance systems for the assessment of physical activity and sedentary behavior among youth and adults in the United States between 2000 and 2019. Results: Over the past 20 years, 8 surveillance systems have assessed physical activity, and 5 of those have assessed sedentary behavior. Three of the 8 originated in nonpublic health agencies. Most systems have assessed physical activity and sedentary behavior via surveys. However, survey questions varied over time within and also across systems, resulting in a wide array of available data. Conclusion: The evolving nature of physical activity surveillance in the United States has resulted in both broad challenges (eg, balancing content with survey space; providing data at the national, state, and local level; adapting traditional physical activity measures and survey designs; and addressing variation across surveillance systems) and related opportunities.
\end{abstract}

Keywords: fitness, public health, exercise, surveys and questionnaires

Surveillance is a core function of public health and is the ongoing systematic collection, analysis, and interpretation of outcome-specific data, which can then be used for planning, implementation, and evaluation of public health practice. ${ }^{1}$ Once there is sufficient evidence that a behavior, such as physical activity, benefits health, 2,3 it is important to include its measurement in public health surveillance systems. Surveillance of physical activity is integral for monitoring physical activity trends over time, setting national goals or objectives regarding physical activity, and understanding which populations are most at risk because of low physical activity levels and related health outcomes. ${ }^{4}$ To this end, physical activity has been assessed in several surveillance systems in the United States and other countries over many years.

Evidence demonstrating the health benefits of physical activity has grown substantially over the years, ${ }^{5,6}$ and public health policies addressing physical activity have evolved as a result (Table 1). For example, early aerobic physical activity recommendations for adults (Table 1) could only consider the existing evidence at the time, which was primarily composed of clinical studies that examined exercise to increase aerobic power. ${ }^{11}$ Over time, as epidemiological studies linked moderate-intensity aerobic activity to health, recommendations and guidelines focused more on unstructured moderate-intensity aerobic activity accumulated weekly. ${ }^{9,10}$ Likewise, more current research linking sedentary behavior to poor health outcomes led to a recommendation to sit less. ${ }^{10}$ Similar changes have occurred in national public health goals, including the Healthy People initiative, which identifies

Omura, Whitfield, Chen, Hyde, Ussery, Watson, and Carlson are with the Division of Nutrition, Physical Activity, and Obesity, Centers for Disease Control and Prevention, Atlanta, GA, USA. Carlson is also with the Division of Population Health, National Center for Chronic Disease Prevention and Health Promotion, Centers for Disease Control and Prevention, Atlanta, GA, USA. Omura (ydk8@cdc. gov) is corresponding author. public health priorities each decade to help individuals, organizations, and communities across the United States improve health and well-being. ${ }^{14}$ For instance, in response to changes in recommendations from the 1995 Centers for Disease Control and Prevention (CDC) and the American College of Sports Medicine to the 2008 Physical Activity Guidelines for Americans (Table 1), ${ }^{8,9}$ the Healthy People 2010 goals for adult physical activity no longer included a target of 30 minutes per day of aerobic physical activity (Table 2). Opportunities and needs for data often emerge from evolving recommendations and Healthy People objectives, which can serve as a catalyst for change in surveillance systems, as it is important for them to correspondingly adapt. For example, in Healthy People 2020, a consistent data source for monitoring the proportion of children aged 6 years and older meeting the physical activity guidelines was not available, and so, a corresponding Healthy People objective was not included. However, in 2016, the National Survey of Children's Health (NSCH) modified its physical activity questions, allowing for assessment of meeting the physical activity guidelines in this age group. Subsequently, a corresponding objective was added in Healthy People 2030.

Public health surveillance of physical activity behaviors has evolved to reflect updated evidence and guidelines, facilitating the monitoring of the proportion of the US population who perform this important health behavior using methods most consistent with current knowledge. Troiano et $\mathrm{al}^{15}$ previously published a review of physical activity surveillance at the national and state levels through 2001, including assessment instruments used in population surveys. Since then, surveillance of physical activity has continued to evolve. For example, in response to the removal of the 10-minute bout recommendation in the Physical Activity Guidelines for Americans, second edition, ${ }^{10}$ the 2020 National Health Interview Survey (NHIS) no longer requires respondents to report only activities lasting at least 10 minutes. ${ }^{16}$ Such changes help keep surveillance systems current with scientific knowledge, but can impact estimates and complicate efforts to document trends in 


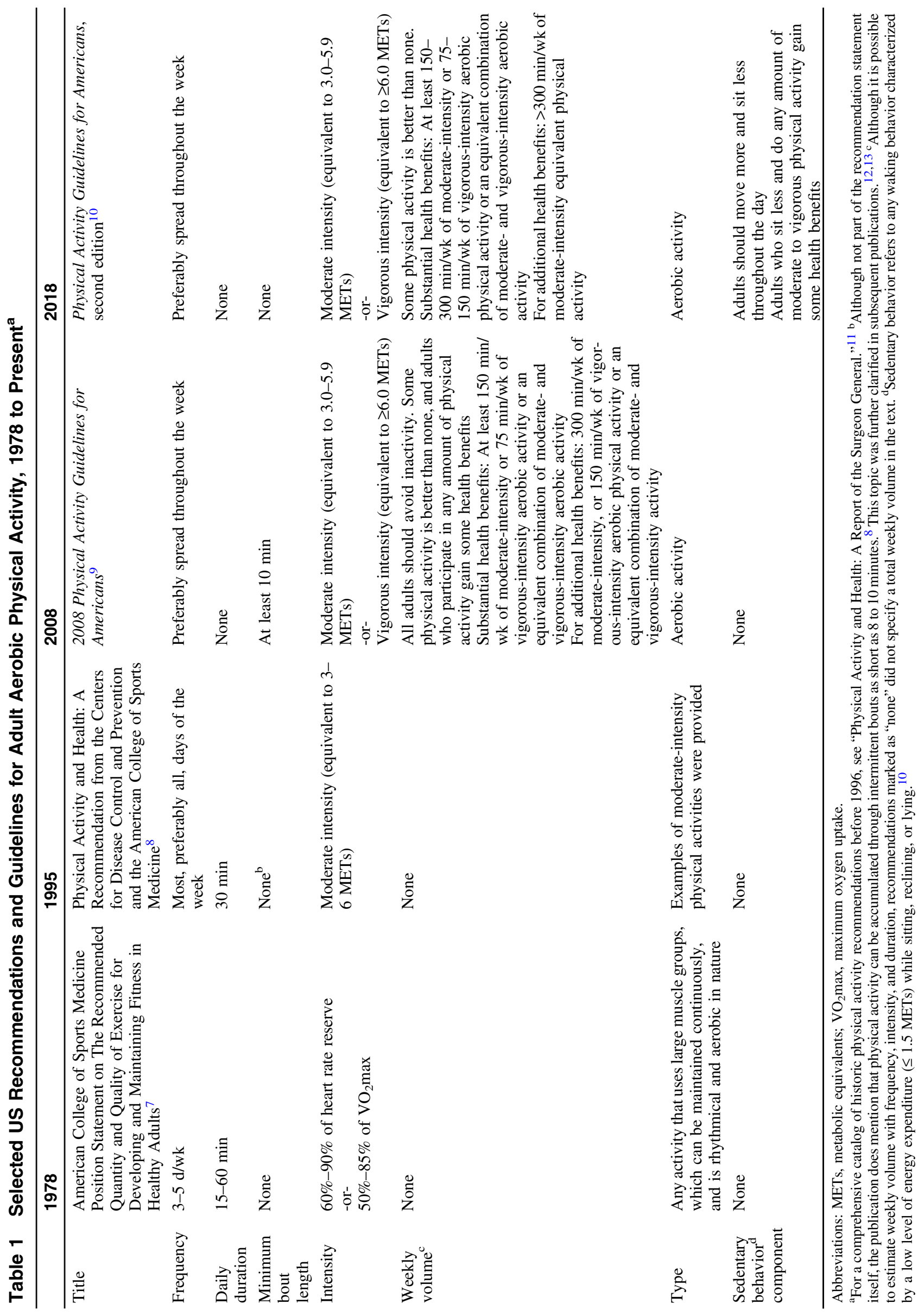



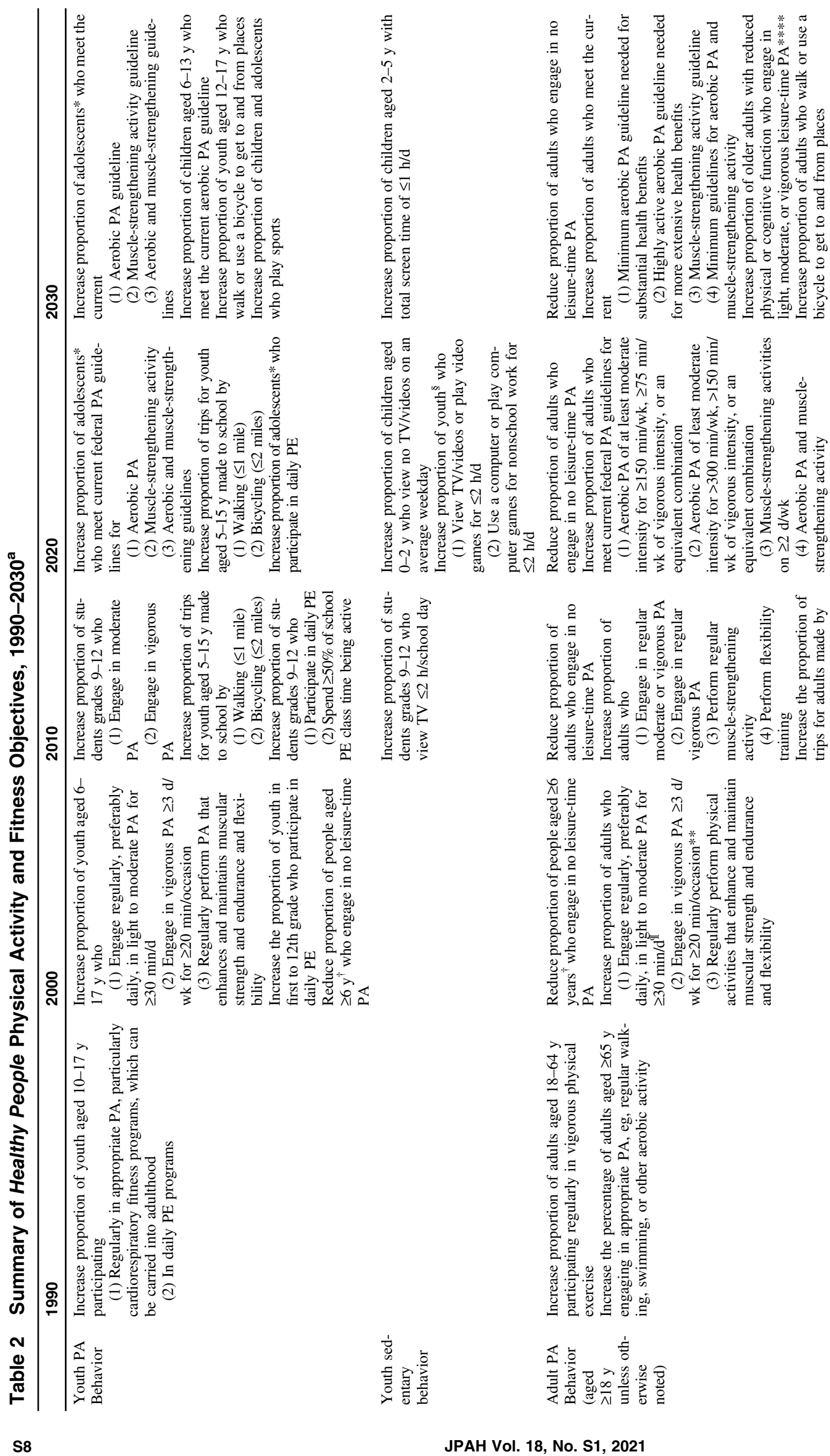

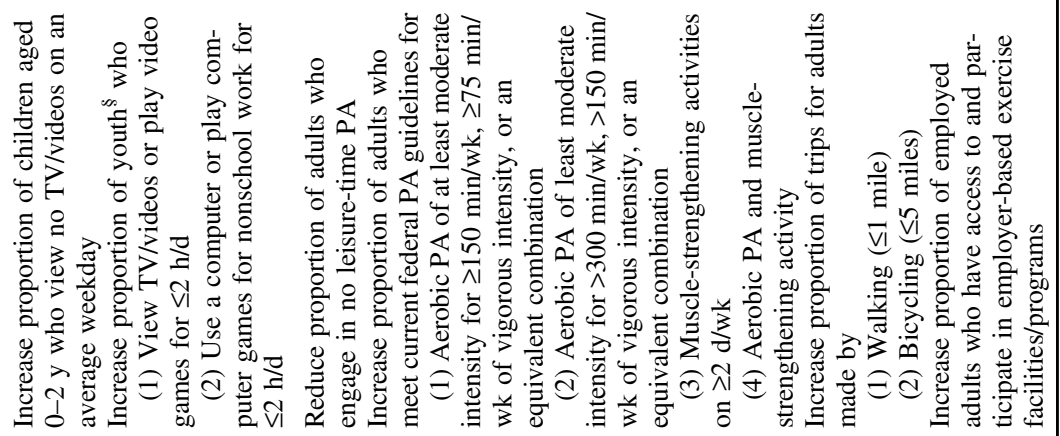

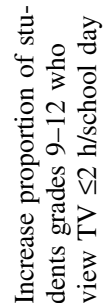
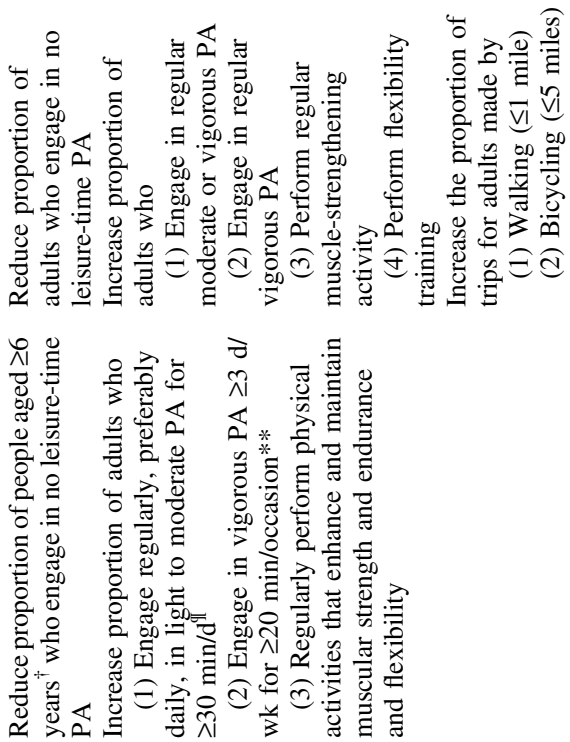

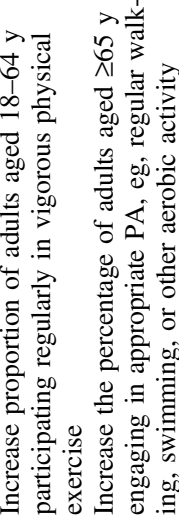

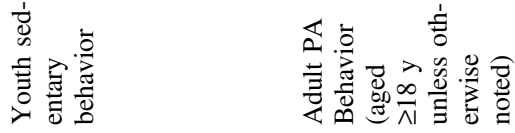




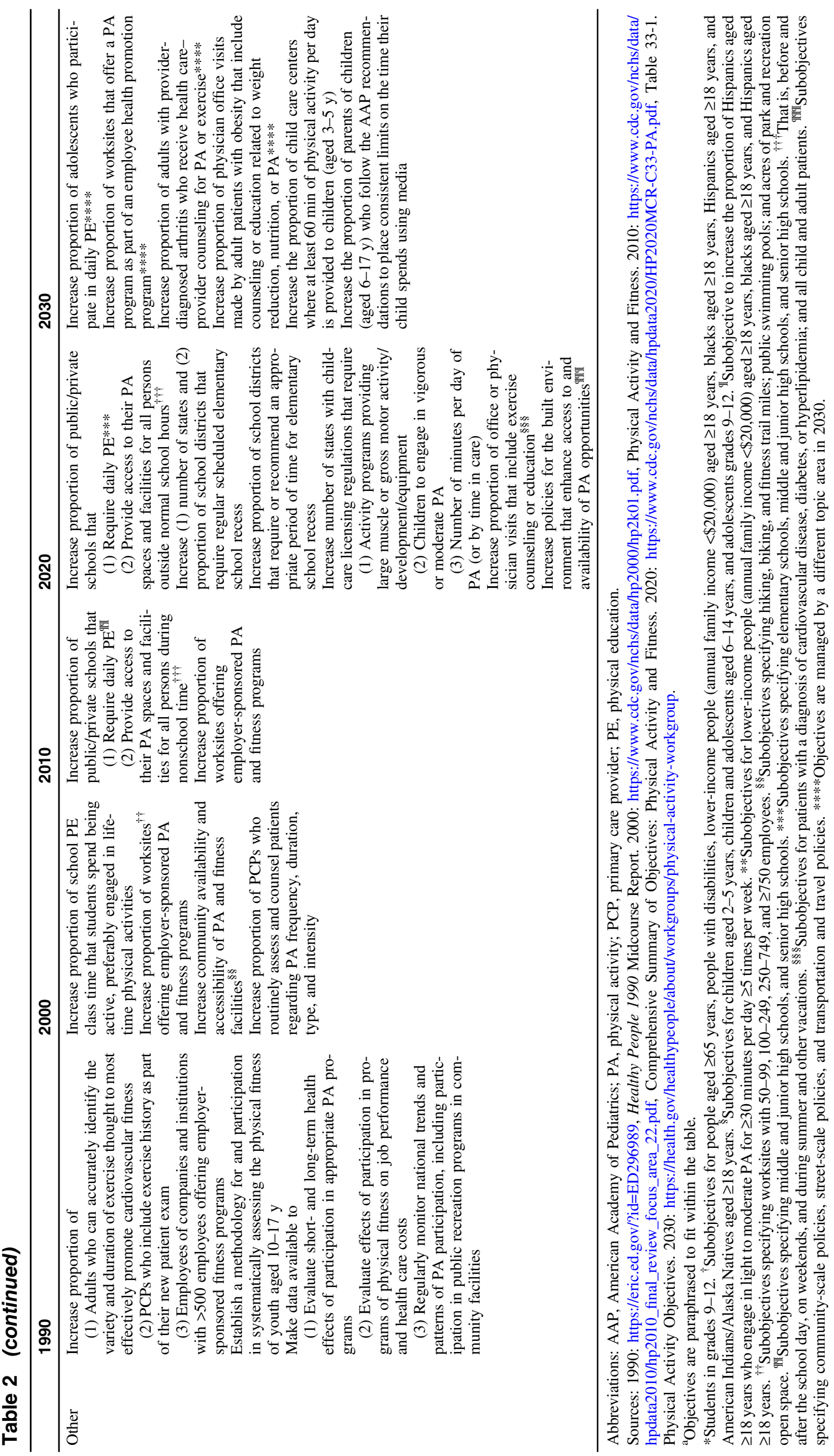


physical activity participation over time. Tracking and reporting changes to physical activity surveillance can assist in the interpretation of physical activity surveillance estimates and reports.

Advances in physical activity assessment and technology can also drive changes in physical activity surveillance. Accelerometers are frequently used to measure bodily movement, which can be an indicator of physical activity behavior. ${ }^{17}$ As use of accelerometers increased in physical activity research, they were incorporated into four 2-year cycles of the National Health and Nutrition Examination Survey (NHANES) between 2003 and $2014{ }^{18}$ Further, the proliferation of cellular telephones and the decline in landline telephones has spurred changes in survey sampling methods to address decreasing response rates of traditional surveys used in several national surveillance systems. ${ }^{19}$ While cell phone technology may negatively impact survey response rates, data derived from cell phones (eg, fitness-tracking app records, activity records collected through passive monitoring) may provide emerging opportunities for monitoring physical activity behaviors. ${ }^{20}$ Understanding the impact of changes in technology is therefore an integral component of discussions regarding opportunities and challenges in physical activity surveillance.

This paper provides a 20-year update to the 2001 Troiano et $\mathrm{al}^{15}$ review of physical activity surveillance. This more recent time period includes critical milestones such as the release of both the 2008 Physical Activity Guidelines for Americans and the Physical Activity Guidelines for Americans, 2nd edition. ${ }^{9,10}$ The primary purpose of this paper is to provide an updated historical overview of the surveillance of physical activity and sedentary behavior at the state and national levels in the United States over the past 20 years. A secondary purpose is to describe current challenges and emerging opportunities impacting physical activity surveillance moving into the future.

\section{Data Sources}

This section provides a brief overview of national and state sources of physical activity and sedentary behavior surveillance data available in the United States (Table 3). Detailed historical and methodological information is publicly available elsewhere for many of these surveillance systems. ${ }^{21-24}$

\section{American Community Survey}

The American Community Survey (ACS) is a nationally ${ }^{25}$ representative survey conducted by the US Census Bureau since 2005. Data collection is continuous, and data are released annually. The Census Bureau selects a random sample of addresses, including group quarters, like college dormitories (since 2006), to be included in the ACS. From 2005 through 2012, the ACS collected data on all persons residing at a sampled address using 3 sequential methods, or "modes": paper questionnaires through the mail, phone interviews, and personal visits with a Census Bureau interviewer. Starting in 2013, the Census Bureau added a fourth mode-an Internet response option. Starting in late 2017, the Census Bureau discontinued using phone interviews to follow up with nonrespondents.

\section{American Time Use Survey}

The American Time Use Survey (ATUS) ${ }^{26}$ began in 2003 and provides annual, nationally representative estimates of how, where, and with whom Americans spend their time. The US Bureau of Labor and Statistics selects participants for ATUS using a stratified, 3-stage sample design including state, households, and an individual within a household. Through a guided telephone interview, ATUS participants give a detailed record of all their activities from the previous day.

\section{Behavioral Risk Factor Surveillance System}

The Behavioral Risk Factor Surveillance System (BRFSS) ${ }^{27}$ began in 1984 and is an annual, state-based system of health surveys that collects information on health-risk behaviors, preventive health practices, and health care access primarily related to chronic disease and injury. BRFSS is a random-digit-dialed telephone survey of the civilian, noninstitutionalized US adult population $\geq 18$ years of age. It is conducted in all 50 states, the District of Columbia (DC), Guam, Puerto Rico, and the US Virgin Islands. Each state works with the CDC to develop a sampling protocol to select households, and 1 adult is selected from each household to participate in the survey. In 2011, BRFSS added survey calls to cell phone numbers and modified their weighting method; due to these methodological changes, data from 2011 and beyond are not directly comparable to previous years of BRFSS data, as shifts in observed estimates are likely to reflect the new methods rather than true trends. ${ }^{28,29}$

\section{National Health and Nutrition Examination Survey}

The NHANES ${ }^{18}$ program began in 1959 and has been conducted as a series of surveys focusing on different population groups or health topics. In 1999, the survey became a continuous program. NHANES combines interviews and physical examinations and uses a stratified, multistage, probability cluster sample of the US civilian, noninstitutionalized population. The NHANES sample is selected in 4 stages: (1) primary sampling units (PSUs, generally counties); (2) segments within PSUs (census blocks or combination of blocks); (3) dwelling units, or households, within segments; and (4) individuals within households. ${ }^{30}$ Nationally representative data are released for each 2-year cycle on the NHANES home page. ${ }^{18}$

\section{National Health Interview Survey}

The NHIS ${ }^{31}$ has been conducted since 1957 and collects information on a variety of health measures. NHIS is primarily a face-to-face household interview survey of a sample of US households, with some interviews also performed via telephone; it is conducted continuously throughout the year, and data are released annually. The survey utilizes a multistage-stratified sampling design that starts by selecting PSUs from a list of geographically designed PSUs that cover the 50 states and DC. The next level of sampling involves selecting households. The sampling plan is redesigned after every decennial census. Basic health and demographic information are collected for all household members; additional information, such as physical activity, is collected on 1 randomly selected adult $(\geq 18 \mathrm{y}$ of age) in each household. Periodically, additional questions related to physical activity are collected from a randomly selected adult and child. NHIS underwent a redesign in 2019; however, physical activity assessment was not included in the 2019 cycle. ${ }^{32}$

\section{National Household Travel Survey}

The National Household Travel Survey (NHTS) is conducted by the Federal Highway Administration and provides comprehensive data on travel and transportation patterns in the United States. It has been conducted in 2001, 2009, and 2017. Prior to the NHTS, the 


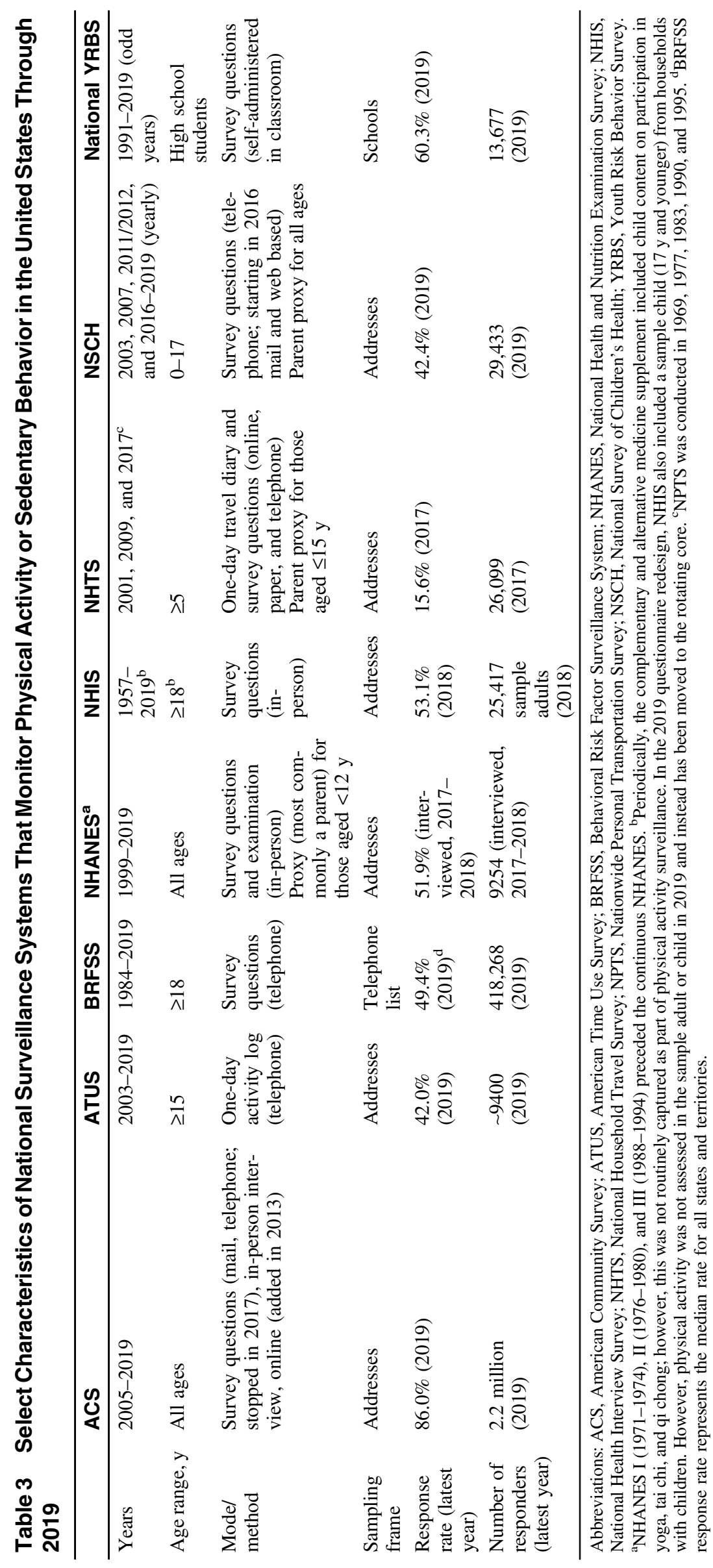


Nationwide Personal Transportation Survey was conducted in 1969, 1977, 1983, 1990, and 1995. The survey includes demographic characteristics of households, people, and vehicles and detailed information on daily and longer distance travel for all purposes by all modes. NHTS survey data are collected from all household members age 5 years and older from a sample of US households and provide national estimates of trips and miles by travel mode, trip purpose, and various household attributes.

\section{National Survey of Children's Health}

The $\mathrm{NSCH}^{33}$ provides representative health data on noninstitutionalized children aged 0-17 years through adult proxy reporting in the United States and in each state. In 2003, 2007, and 2011/2012, the NSCH was a national telephone survey using a list-assisted random-digit-dial sample of landline telephone numbers within nonoverlapping areas, supplemented with an independent randomdigit-dial sample of cell phone numbers in 2011/2012 only. It was conducted by the National Center for Health Statistics using the same sampling frame as the CDC's National Immunization Survey. If more than one child lived in the household, only one child was randomly selected to be the subject of the detailed interview; a parent or guardian respondent in the household who knows about the health and health care of the selected child was interviewed as an adult proxy for the child.

Starting in 2016, the NSCH transitioned to a self-administered mail- and web-based survey conducted annually by the US Census Bureau on a random address-based sample of households. After stratifying by state and a child-presence indicator, the strata of addresses more likely to have children are oversampled. A screener survey is used to determine households with children (0-17 y) and create rosters of these children with corresponding demographic information. Children with special health care needs and children aged 0-5 years are oversampled. One child per household is then randomly selected, and a parent or guardian respondent in the household who knows about the health and health care of the selected child is given an age-specific topical survey regarding the child, to report as an adult proxy.

\section{Youth Risk Behavior Survey}

The Youth Risk Behavior Surveillance System (YRBSS) includes ongoing national, state, territorial, tribal, and large urban school district surveys, of which the national Youth Risk Behavior Survey $(\mathrm{YRBS})^{34}$ is one. The YRBS, as part of the YRBSS, has been conducted by the CDC every other year since its beginning in 1991 . It is a self-administered school-based survey of a nationally representative sample of US public and private school students in grades $9-12$ in the 50 states and DC. The national survey is administered to ninth- through 12th-grade students drawn from probability samples of schools and students. It uses a 3-stage cluster sample design, with the first-stage sampling frame of counties as PSUs. The PSUs are categorized into 16 strata by metropolitan statistical area status and black and Hispanic student percentages. Next, in the second-stage sampling frame, schools with grades 9-12 are sampled from those PSUs.

\section{Reported Aerobic Activity}

This section presents the various assessments of aerobic activity across systems, organized as surveys of children and adolescents, surveys of adults, and time-use or trip-diary data.

\section{Surveys of Children and Adolescents}

The surveillance systems that collect information about physical activity in children and adolescents via survey questions are the NHANES, NHIS, NHTS, NSCH, and YRBSS (Table 4).

Questions specific to youth on NHANES have differed across the years. From 1999 to 2008, parents of children aged 2-11 years were asked how many days their child participated in vigorous physical activity (eg, that makes them sweat and breathe hard). From 2009 to 2020, NHANES assessed how many of the past 7 days youth engaged in $\geq 60$ minutes of moderate to vigorous physical activity (eg, that increases heart rate and makes breathing hard some of the time), although included age groups differed across the years. A proxy, most commonly a parent, reported for their children aged less than 12 years, and those aged 12 years and older self-reported. From 2013 to 2016, more extensive questions were included as part of the NHANES questionnaire, assessing physical activity outside of the school day (ages 3-15 y), vigorous activity (ages 5-15 y), and participation in sports or physical activity clubs (ages 5-15 y). Many NHANES questions assessing moderate- and vigorous-intensity activity for those aged 12 years and older are the same as those asked of adults and are covered in the next section and in Table 4.

The NHIS has periodically included physical activity-related questions among children. For example, the complementary and alternative medicine supplement included child content on participation in yoga, tai chi, and qi chong. ${ }^{35,36}$ However, these questions have not been used as part of routine national surveillance of children's physical activity. The NHTS examined physical activity among children and adolescents aged 5 years and older, with adult household members serving as proxies for those below 16 years of age. The included questions assessed episodes of (1) outdoor walking and (2) biking (for exercise only, 2001 and 2009; overall and for exercise, 2017). In 2017, NHTS also asked about days engaged in at least 30 minutes of (1) vigorous activity and (2) moderate activity for those aged 5 years or older. Finally, the NHTS included questions in 2009 and 2017 about active transportation to school, assessed as the usual mode of transportation (eg, biking or walking) to school.

In 2003, 2007, and 2011/2012, the $\mathrm{NSCH}$ asked parents about the number of days children engaged in vigorous activity for $\geq 20$ minutes. Starting in 2016, this question was removed and replaced with a question about the number of days in the past week children engaged in physical activity (eg, exercise, play a sport, or participate in physical activity) for $\geq 60$ minutes. Parents were also queried about whether children participated in sports teams or lessons.

From 1993 to 2009, the YRBS asked high school students to report how many days in the past 7 they engaged in $\geq 20$ minutes of vigorous activity (eg, that makes them sweat and breathe hard), and from 1999 to 2009, students also reported days engaged in $\geq 30$ minutes of moderate activity (eg, that does not make them sweat or breathe hard). From 2005 to 2019, the YRBS asked high school students to report how many days in the past 7 they engaged in $\geq 60$ minutes of moderate to vigorous physical activity (eg, that increases heart rate and makes breathing hard some of the time); however, due to changes in the sequence of the survey questions in 2011, questionnaire changes preclude a comparison of this question for 2009 and earlier with 2011 and later. From 1991 to 2019, high school students were asked about how many days they go to physical education classes, along with additional questions about minutes of exercise during physical education class included from 1991 to 2009. From 1991 to 2019, students were also asked 


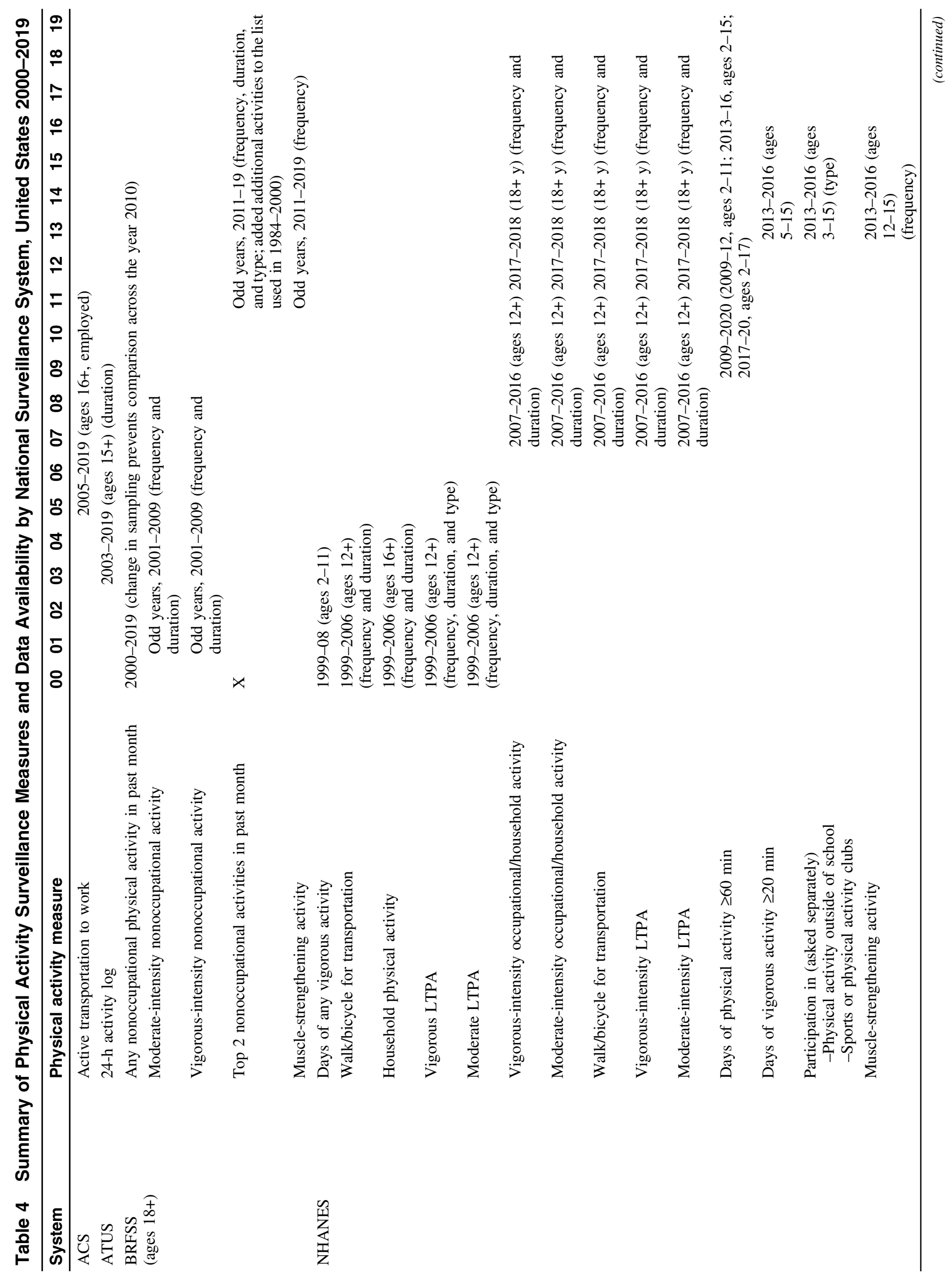




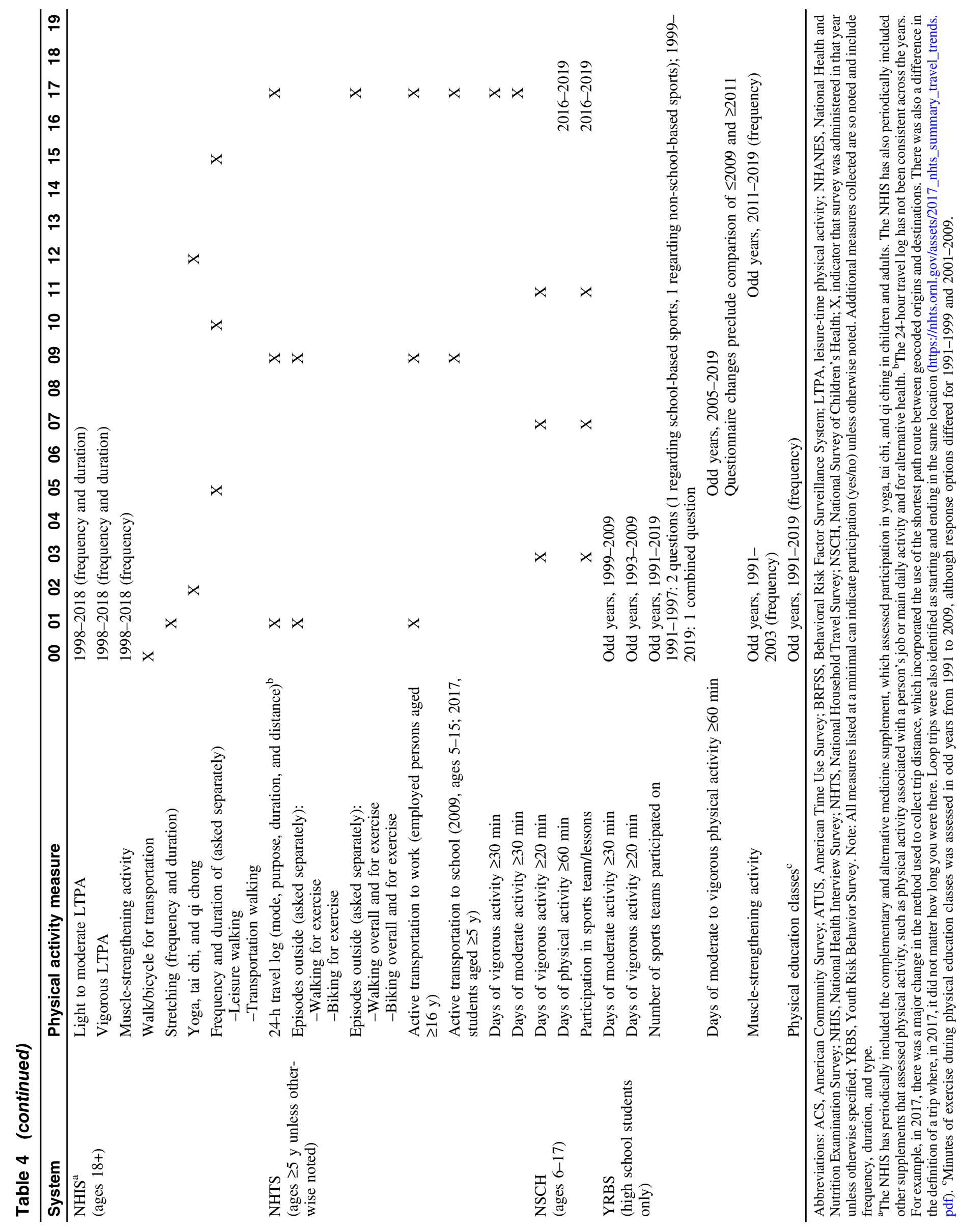


whether they had played on sports teams during the previous 12 months.

\section{Surveys of Adults}

For adults, the main surveillance systems that collect self-reported information about physical activity include BRFSS, NHANES, and NHIS (Table 4). ACS and NHTS contain a more limited number of physical activity survey questions. Each of these systems has a long and varied history of collecting physical activity data.

The BRFSS has tracked physical activity in 2 different ways. First, a single core question about past-month participation (yes/no) in any nonoccupational physical activities or exercises, such as running, calisthenics, golf, gardening, or walking, has the longest history on the BRFSS. ${ }^{37}$ In 1984, 35 states included this question on their BRFSS core. By 1996, all states had incorporated this question as part of the BRFSS core; this question is often referred to as the BRFSS Physical Activity Tracking Question. From 1984 to 1991, in even years from 1992 to 2000, and in odd years from 2011 to 2019 , BRFSS physical activity questions assessed the 2 nonoccupational physical activities each adult spent the most time doing during the past month, including frequency and duration. The relative intensity of each reported activity is estimated to determine if the activity is of moderate or vigorous intensity for each respondent. Relative intensity takes into account the respondent's maximal oxygen uptake, which is estimated based on their sex and age. In odd years from 2001 to 2009, BRFSS included different questions; respondents were asked to recall overall frequency and duration of time spent doing nonoccupational physical activities of moderate intensity (eg, small increases in breathing or heart rate) and of vigorous intensity (eg, large increases in breathing or heart rate) in a usual week for at least 10 minutes at a time.

Prior to 1999, the physical activity assessment in NHANES was of limited scope. Starting with the continuous NHANES that began in 1999, the physical activity section expanded. From 1999 to 2006, the NHANES respondents were asked how many days in the past month and for how long each day they walked or biked for transportation. Frequency (eg, how often) and duration (eg, for how long each time they participated for at least $10 \mathrm{~min}$ ) were also assessed separately for each the following types of activity: (1) moderate-intensity or greater household physical activity, (2) vigorous-intensity leisure-time physical activity (eg, running, lap swimming, aerobics class, fast bicycling), and (3) moderateintensity leisure-time physical activity (eg, brisk walking, bicycling for pleasure, golf, or dancing). Also, the type of vigorous- and moderate-intensity leisure-time activities performed over the past 30 days was assessed. From 2007 to the present, NHANES respondents have been asked how often in the past month and for how long each time they participated for at least 10 minutes continuously in (1) vigorous-intensity work or household-related physical activity, whether paid or unpaid (eg, carrying or lifting heavy loads, digging or construction work); (2) moderate-intensity work- or household-related physical activity, whether paid or unpaid (eg, brisk walking or carrying light loads); (3) transportation-related walking or biking (assumed moderate intensity); (4) vigorous-intensity sports, fitness, or recreational physical activity (eg, running or basketball); and (5) moderate-intensity sports, fitness, or recreational physical activity (eg, brisk walking, bicycling, swimming, or golf).

Prior to 1997, the physical activity assessment in NHIS was inconsistent and has been previously described. ${ }^{15}$ In 1997, as part of the NHIS questionnaire redesign, physical activity questions were included in the core questionnaire for the first time. From 1998 to 2018, a series of leisure-time physical activity questions assessed the frequency and duration of physical activity that occurred for at least 10 minutes at (1) light to moderate intensity and (2) vigorous intensity. A separate question was included on the frequency of muscle-strengthening activity. In 2005, 2010, and 2015, as part of the Cancer Control Supplement, the NHIS also included questions on leisure and transportation walking (frequency and duration) that took at least 10 minutes. In addition to the questions related to walking, other supplements have periodically included questions to assess physical activity behavior. For example, supplements have included questions related to physical activity associated with a person's job or main daily activity and for alternative health. ${ }^{38}$ In 2019, the NHIS questionnaire underwent a major redesign. This included the physical activity questions, which were revised slightly from the 2018 version and will appear every 2 years starting in 2020, along with a series of questions on leisure and transportation walking. Revisions include the removal of light-intensity activity from the questions assessing moderate-intensity activity and removal of the 10-minute bout requirement for physical activity and walking questions.

Two surveys, the ACS and the NHTS, have more limited physical activity assessments. ACS and NHTS query employed adults about their mode of transportation to work. Since 2005, the national ACS has asked employed persons aged 16 years and older about their primary mode of transportation in the preceding week, and response options include walking and biking. Similar to ACS, the 2001, 2009, and 2017 NHTS also assessed the primary mode of transportation to work in the preceding week for all employed persons aged 16 years and older, and the responses included walking and biking. As highlighted in the section for youth, the NHTS also included questions for those aged 5 years or older about episodes of (1) outdoor walking and (2) biking and about days engaged in at least 30 minutes of (1) vigorous activity and (2) moderate activity.

\section{Time Use or Trip Diary Data}

Two surveillance systems (ATUS and NHTS) collect diary information that permit assessment of different physical activity constructs. The ATUS interview records all activities for a respondent from the previous day and can be used to estimate time spent in various physical activities. The ATUS collects data in enough detail to link ATUS primary activity codes with metabolic equivalents cataloged in the Compendium of Physical Activities. ${ }^{39,40}$ Also, there are opportunities to use multiple data elements within ATUS to identify different types of physical activity. For example, activities coded as travel can be considered active transportation if they were reported to occur during walking or bicycling. ${ }^{41}$

The NHTS collects data on trips taken in a 24-hour period for a randomly assigned day of the week. Trip log retrieval was conducted for all household members in 2001 and all members aged 5 and older (adult proxy for children aged 5-15 y) in 2009 and 2017. The information collected includes the purpose of the trip (work, shopping, etc), means of transportation used (car, bus, subway, walk, etc), trip distance, and trip minutes. The NHTS trip data can be used to examine trips that were made using active transportation (ie, walking or bicycling as a means of transportation) and can also be used to examine the mode of transportation used to get to specific destinations, such as school for children and adolescents. Collection prompts and details have differed somewhat over the 
years, so differences in data collection techniques should be carefully examined when using data from the trip diary for examining trends. For example, the 2017 NHTS changed the definition of a trip to allow walk and bike trips to and from home (loop trips) that were not included in previous years. ${ }^{42}$

\section{Reported Muscle-Strengthening Activity}

The frequency of muscle-strengthening activity is assessed via questionnaire among both adolescents and adults (Table 4). NHANES and YRBS have assessed muscle-strengthening activity in adolescents. Specifically, the NHANES questionnaire assessed muscle-strengthening activity for those aged 12 years and older from 1999 to 2006 and for those aged 12-15 years from 2013 to 2016 . The YRBS asked high school students about their frequency of participation in muscle-strengthening activity from 1991 to 2003 and 2011 to 2019. For adults, an assessment of muscle-strengthening frequency is included in BRFSS for 2011-2019, NHIS for 1998-2018, and NHANES for 1999-2006.

\section{Reported Sedentary Behavior}

\section{Surveys of Children and Adolescents}

The survey-based surveillance systems that collect information about sedentary behavior in children and adolescents include NHANES, NSCH, and YRBSS (Table 5). These systems mainly focus on screen time (eg, TV viewing, computer usage), with the 1 exception being NHANES, which assessed sitting time among all respondents aged 12 years and older from 2009 to 2016.

Although exact questions differed over time, all 3 systems have a similar history of assessing screen time. Two systems started with 1 question assessing TV viewing only (NSCH 2003 and 2007, YRBS 1999 and 2001), and NHANES included a question combining TV viewing and computer use from 1999 to 2002 for those aged 16 years and older. Next, each system included separate questions about TV and computer use (NHANES 1999-2018; NSCH 2011/2012, 2016, and 2017; YRBS 2003-2019), although the examples included within the computer use questions have changed periodically, and the age groups assessed have changed for NHANES over time. Most recently, NHANES 2019-2020 and NSCH 2018-2020 switched to a single screen time question. NHANES 2019-2020 assessed the average hours in a typical school day spent playing with a smartphone or computer, watching TV or movies, or playing video games. NSCH 2018-2020 assessed the average hours in a typical school day spent in front of a TV, computer, cell phone, or other electronic device, watching programs, playing games, accessing the Internet, or using social media, not including time spent doing schoolwork.

\section{Surveys of Adults}

Some screen time questions in NHANES have periodically included adults, as well as youth, including the question combining TV viewing and computer use in 1999-2002 and the separate questions about TV viewing and computer use from 2003 to 2006 and 2011 to 2016 (Table 5).

For adults, NHANES has the longest history of collecting data on sitting time. NHANES 2007-2008 assessed the time spent sitting or reclining on a typical day, and then "reclining" was removed for NHANES 2009-2020 (2009-2016, ages 12 y and older; 2017-2020, ages 18 y and older). Questions assessing time spent sitting during weekdays and weekend days among adults were also included in the 2000 and 2005 NHIS Cancer Control Supplement.

\section{Time Use Data}

Similar to using the ATUS for estimating physical activity participation, intensity (MET) coding of the ATUS data allows for the classification of activities and occupations as sedentary (1.0-1.5 metabolic equivalents). ${ }^{40}$ Examples of activities classified as sedentary are eating and drinking and watching TV.

\section{Device-Collected Human Movement}

The NHANES is the only national surveillance system that has periodically included measures of human movement assessed via a device (Table 6). In 2003-2006, all ambulatory examination participants aged 6 years and older were asked to wear the ActiGraph 7164 (Pensacola, FL) device on a waist belt during waking hours for 7 days and to remove the device only for waterbased activities. ${ }^{18}$ In 2011-2014, all examination participants aged 6 years and older (ages 3-5 y were added in 2012) were asked to wear the water-resistant ActiGraph GT3X+ on a wrist band at all times for 7 days and 8 nights. ${ }^{18}$ Most commonly, accelerometer output has been translated into categories of activity intensity based on predicted energy expenditure, which are then used to create national estimates of time spent in light-, moderate-, and vigorousintensity physical activity and sedentary behaviors. ${ }^{17,43}$ However, accepted standardized thresholds for classifying activity intensity using wrist-worn accelerometers do not currently exist; thus, activity-intensity categories are not provided for the 2011-2014 NHANES accelerometer data. ${ }^{44}$

\section{Test-Based Fitness and Strength Assessments}

Though not direct measures of physical activity behaviors or movement, cardiovascular fitness and muscular strength are physiological parameters that are related to physical activity. NHANES has periodically included testing related to fitness and muscle strength (Table 6). Cardiovascular fitness testing via submaximal exercise testing was conducted as part of NHANES 1999-2004 for respondents aged 12-49 years and, in 2012, among youth aged 615 years. Muscle strength has been tested periodically in NHANES via different procedures (Table 6). This testing was done for those aged 50 years and older in each cycle from 1999 to 2004 and for those 6 years and older in each cycle from 2011 to 2014, although the types of assessments differed slightly. In addition, the NHANES National Youth Fitness Survey was conducted in 2012 and included multiple additional tests of cardiovascular capacity, performance endurance, core strength, and upper- and lower-body strength for youth aged 3-15 years.

\section{Discussion}

Over the past 20 years, national and state surveillance systems have used a variety of measures to monitor physical activity and sedentary behaviors among children, adolescents, and adults, resulting in a wide array of available data. This evolving nature of physical activity surveillance in the United States has resulted in 


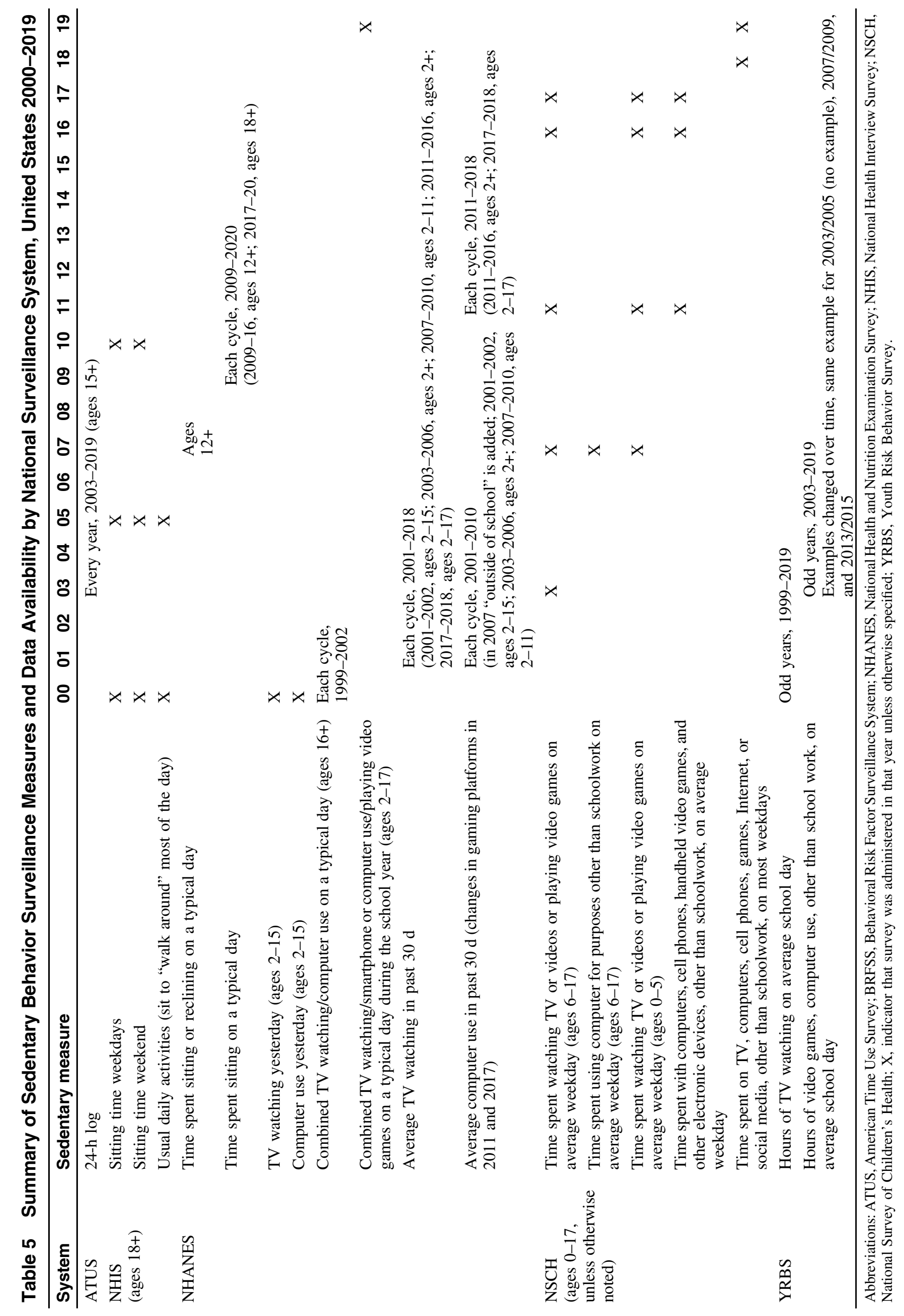




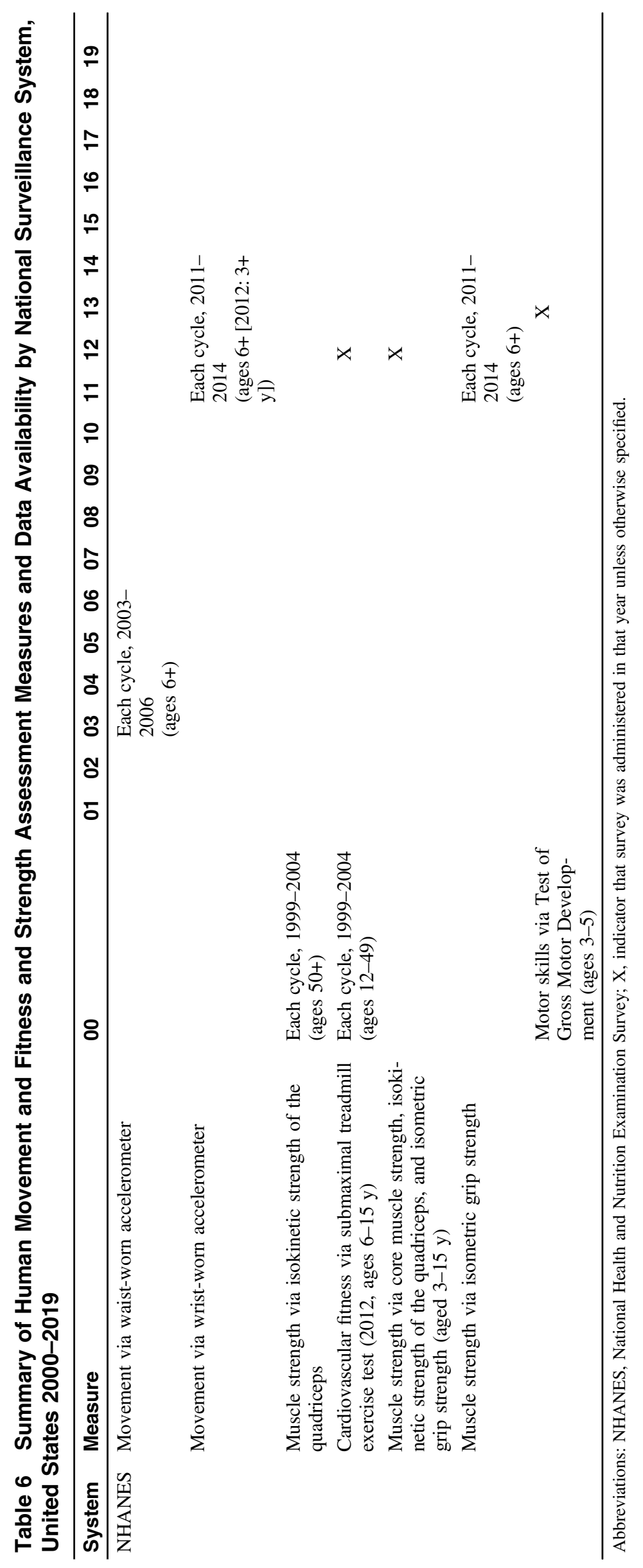


data that can be used for a variety of public health purposes, as well as broad challenges and related opportunities.

\section{Data Availability and Uses}

Data from surveillance systems that measure and track changes in physical activity behavior can be used for many purposes. These include setting health goals or objectives, monitoring trends in physical activity over time, creating public awareness of physical activity as an important health behavior, identifying populations at high risk and related health disparities, developing and evaluating programs, supporting health-related policy or legislation, and examining relationships of interest (eg, relationships between behavior and health outcomes or between policy changes and changes in behavior). ${ }^{4}$ Making physical activity surveillance data and related estimates easily accessible for researchers and practitioners can facilitate data use. All data systems highlighted in this manuscript provide public-use data sets. Further, several of the surveillance systems offer summary reports (eg, NHIS, YRBSS) ${ }^{45-}$ 47 or have related web-enabled tools (eg, ACS, BRFSS, NHTS, $\mathrm{NSCH}, \mathrm{YRBSS})^{48-51}$ that provide estimates for various indicators, including those related to physical activity, by selected demographic and geographic characteristics. In addition, these surveillance systems and their resulting data can help inform global efforts. In particular, NHANES's physical activity questions are based on the International Physical Activity Questionnaire. This facilitates international comparisons, as the International Physical Activity Questionnaire is the basis for physical activity estimates in many countries. ${ }^{52}$

Most available physical activity estimates focus on current physical activity guidelines (Table 1) or Healthy People objectives (Table 2). The Healthy People 2020 data portal and the CDC Division of Nutrition, Physical Activity, and Obesity's "Nutrition, Physical Activity, and Obesity: Data, Trends, and Maps" interactive database provide estimates across different physical activity surveillance systems, as well as estimates stratified by select demographic and geographic characteristics and year. ${ }^{53,54}$ In addition, many journal articles provide an in-depth examination of long-term trends in physical activity, correlates of physical activity, and associations between these physical activity variables and health. ${ }^{37,41,55-69}$ For example, a number of articles have examined trends and correlates of walking for leisure and transportation using the NHIS walking questions. ${ }^{64-69}$

The limited assessment of sedentary behavior, device-collected human movement, and fitness testing across surveillance systems has led to less widely available estimates than those of aerobic and muscle-strengthening activity. For sedentary behavior, estimates of self-reported sitting time among adults can be found in published literature. ${ }^{40,55,70-72}$ For example, Ussery ${ }^{72}$ found that self-reported sitting time among US adults increased from 5.5 hours per day in $2007 / 2008$ to 5.9 hours per day in 2017/2018. Screen time estimates as a proxy for sedentary behavior for children and adolescents are more readily available on several data portals, including the Healthy People 2020 data portal and CDC's Youth Online portal. ${ }^{53,73} \mathrm{~A}$ number of studies have used device-collected human movement data, such as accelerometer-based measures from the 2003 to 2006 NHANES, to assess physical activity levels and sedentary time among youth and adults in the United States, although more recent national estimates are lacking. ${ }^{17,74-76}$ In addition, estimates regarding fitness testing are similarly limited. For example, only a few publications have examined cardiorespiratory fitness levels among youth, muscular strength in children and youth, and cardiorespiratory fitness levels among US adults 20-49 years of age. ${ }^{77-83}$ A single previous study also combined aerobic activity, sedentary behavior, and fitness assessments by examining the associations of youth physical activity and screen time with fatness and fitness in children and adolescents. ${ }^{84}$

\section{Challenges and Related Opportunities}

The challenges and related opportunities for physical activity and sedentary behavior surveillance have been highlighted in previous publications, which include recommendations and suggestions for enhancing national physical activity surveillance. ${ }^{15,85}$ However, these papers do not fully capture the past 2 decades. Given that the current review provides an update to cover the past 20 years of physical activity surveillance in the United States, we highlight current challenges and related opportunities.

Identifying and Filling Assessment Gaps. Public health surveillance systems (eg, NHIS, NHANES) generally include physical activity questions that allow analysts to categorize individuals into groups based on physical activity guidelines and Healthy People objectives. ${ }^{10}$ As outlined previously, the main components of the physical activity guidelines (ie, frequency, duration, and intensity) are captured in multiple systems, with a few notable exceptions where additional assessment is needed. ${ }^{10}$ For example, there is currently a lack of data on muscle-strengthening activity among children younger than high school age; muscle-strengthening duration and volume in general; bone-strengthening activity among children and adolescents; vigorous-intensity activity among children and adolescents; and multicomponent activity, which includes balance training along with aerobic and muscle-strengthening activity among older adults. ${ }^{10}$ Additionally, the assessment of specific activity types, such as balance training, is rare in existing surveillance systems, and activity across multiple domains, such as occupational physical activity, is limited. A better understanding of these components can provide useful information to examine the role of occupational physical activity on health and for designing and monitoring the impact of physical activity promotion programs, such as group exercise and fall-prevention programs for older adults that include aerobic exercise, strength training, and balance training. ${ }^{86}$ For sedentary behavior, current assessment is mainly limited to a single question assessing total sitting time in adults and various questions assessing screen time, usually in youth. More detailed information about various domains in which sedentary behavior occurs (eg, occupational, transportationrelated) may inform strategies to reduce sedentary time. Filling these identified gaps would help public health professionals and researchers more completely describe physical activity participation and sedentary behavior in the United States and design-related interventions.

When designing and refining questions for surveillance systems that might address these gaps, it is necessary to balance the level of detail needed with questionnaire brevity. When preference is given to brevity, opportunities may exist to supplement data with periodic survey supplements. For example, the 2010 National Youth Physical Activity and Nutrition Study was a cross-sectional, school-based study conducted by the CDC that included a survey collecting information on behaviors and behavioral determinants related to nutrition and physical activity among high school students. ${ }^{87}$ In addition, the NHANES National Youth Fitness Survey was conducted in 2012 to collect data on physical activity and fitness levels, providing an evaluation of the health and fitness of children in the United States aged 3-15 years. ${ }^{88}$ 
Providing Data at the National, State, and Local Level. Locallevel data can help local policy makers and public health professionals plan, monitor, and evaluate physical activity programs. Although many systems provide estimates at the state level (eg, ACS, ATUS, BRFSS, NHTS, NSCH, YRBSS), these existing systems do not have sufficient sample sizes to produce direct estimates for most areas below the state level (eg, county, city, place, or in the case of YRBSS, the school district), with the exception of the ACS. While local-level data are important, sufficiently increasing sample sizes to produce local-level estimates within systems may be challenging.

In the absence of producing direct estimates, small-area estimation techniques, especially the statistical model-based approaches, have been applied to national or state health surveys to generate reliable small-area estimates. ${ }^{89-91}$ For example, the PLACES project is a collaboration between the CDC, the Robert Wood Johnson Foundation, and the CDC Foundation. ${ }^{92}$ The purpose of the PLACES project is to provide model-based estimates at the county, place (incorporated and census-designated places), census tract, and ZIP Code Tabulation Area level for 27 chronic disease risk factors, health outcomes, and clinical preventive service use for the entire United States. ${ }^{92}$ The PLACES project includes small-area estimates of the prevalence of adults who report no leisure-time physical activity. ${ }^{92}$ These estimates can help with public health planning, although they are not currently useful for evaluation or tracking changes at the local-level over time. ${ }^{89-91}$

Traditional Physical Activity Measures. In general, the estimates reviewed in this report are based on surveys that collect physical activity data using self- or proxy-report methods. However, such self-reported data have several limitations, including recall and social desirability biases. ${ }^{93}$ These biases have been shown to result in overestimates of physical activity behavior and underestimates of sedentary behavior. ${ }^{85,93-97}$ Additional challenges are related to questions assessing screen time and sedentary behavior. ${ }^{99-100}$ For example, screen time questions, often used as a proxy for sedentary behavior, do not account for sedentary behaviors that occur outside time spent using screens; may measure TV, new technologies, and interactive or social media use together or separately, and only outside the scope of schoolwork for youth; and may not measure media multitasking (eg, screen time during physical activity or using multiple media simultaneously). ${ }^{98-101}$ Single-item, self-reported measures of sitting time among adults have been shown to underestimate the total sedentary time, and the aggregate measures may not reflect true population estimates. ${ }^{102}$

Device-based assessment methods can measure human movement, an important component of physical activity behavior, and help reduce the previously described challenges of reported active and sedentary behaviors. However, incorporating device-based measurement into a surveillance framework presents several challenges itself, including the cost, along with the complexity of the devices and analyzing the data they provide. ${ }^{85}$ In addition, the evolving technology makes it difficult to consistently measure and track changes over time. For example, although accelerometers were incorporated into NHANES twice, the different devices and protocols used (eg, waist-worn vs wrist-worn) make it difficult to compare these data. ${ }^{85,103}$ An additional challenge of wearable devices for physical activity surveillance is the lack of standard metrics or cut points for defining participation in moderate- and vigorous-intensity activity.$^{85}$ Device-based measures alone are also unable to provide information on the context or purpose of the activity recorded. Finally, current physical activity guidelines were based largely on the associations between reported physical activity and health, not human movement data and health. ${ }^{3,85}$ Guidelines based on human movement data have not been established, making standardized reporting of device-based data assessing movement more challenging. ${ }^{85}$ Despite these limitations, device-based assessment methods offer an important opportunity for physical activity surveillance. Expanded use can help clarify and resolve outstanding questions, along with efforts to establish physical activity guidelines based on human movement data.

Traditional Survey Designs. Surveillance relies on the ongoing systematic collection of data. Some national surveillance systems that measure physical activity have revised their methods and measures over time, which limits the ability to make comparisons before and after the changes occurred. Traditional survey-based surveillance systems also take time to collect, process, and report data, which can limit their timeliness. Moreover, all of the surveillance systems described here depend upon their ability to reach and engage potential survey respondents. ${ }^{19}$ Declining response rates present a challenge to the viability of such surveys. Response rates over the past 20 years have declined, including the NHIS sample adult section (response rate: $72.6 \%$ in 1998 to $63.4 \%$ in 2018) and the BRFSS (median state-level response rate: $59.2 \%$ in 1998 and $49.9 \%$ in 2018). ${ }^{104-107}$ The pervasiveness of cell phones and lack of landlines is especially problematic for surveys that rely on lists of telephone numbers for sampling, although many systems have updated their sampling methods to address these issues. ${ }^{19,28}$ For example, in 2011, BRFSS added new procedures to include cellular telephone households and modified their weighting method to adjust survey data for differences between the demographic characteristics of respondents and the target population. ${ }^{28,108}$ Other strategies to maximize response rates include incentives, addressbased sampling, utilizing multiple modes, 2-phase sampling, responsive design, and retaining respondents in panel surveys. ${ }^{19}$

New assessment methods and technologies may provide alternative data sources that can complement traditional physical activity and sedentary behavior data sources. ${ }^{85,109}$ These types of emerging data are being explored across multiple sectors. For example, a 2020 study reviewed emerging data sources for pedestrian and bicycle monitoring and categorized them based on whether the mode used can be detected with no or little effort. ${ }^{20}$ Examples identified in this review included those with mode-unspecified data (eg, cell-tower mobile phone positioning, multiapp location-based service, Wi-Fi/ Bluetooth) and mode-specified data (eg, regional bicycle-tracking app, fitness-tracking app, bike-share program). ${ }^{20}$ Moving forward, sectors can work together to better understand how these emerging data are captured, explore the validity of measures and the representativeness of data, develop solutions to data access and privacy concerns, and further explore the feasibility of using these sources for public health surveillance purposes. ${ }^{85}$

Crowd-sourced human movement data using wearable activity monitors, such as smartphone apps and wearable devices, is another possible source for national physical activity surveillance. ${ }^{85,109-112}$ Previous studies in this area have generally found that users of wearable activity monitors are not representative of the overall US population and are notably more active than the general population. ${ }^{110-112}$ Ownership and sharing of data from commercial wearable activity monitors pose additional challenges. Future research examining methods to overcome such limitations may help improve the potential application of these data for national physical activity surveillance.

The health care sector also holds potential as an emerging source of physical activity surveillance data. An expert panel convened by the National Academies of Science recommended several 
sector-specific strategies, including those in the health care sector, to enhance public health surveillance of physical activity. ${ }^{113}$ The strategies recommended included developing surveillance systems to monitor the prevalence of physical activity assessment in health care delivery through expanded integration of a standard physical activity vital sign and expanding the use of data from wearable devices for monitoring physical activity in at-risk patients. ${ }^{113}$ The latter recommendation may be particularly useful, since users of wearable devices are most willing to share their data with their health care provider. ${ }^{110-112,114}$

Communicating Variation Across Surveillance Systems. Given the number of surveillance systems that measure physical activity using various measures and survey designs, it is not surprising that variation exists in physical activity estimates across surveillance systems. ${ }^{61,85,115}$ However, this presents a challenge in interpreting and communicating these differing estimates. ${ }^{85}$ Experts have previously recommended methods to improve communication, translation, and dissemination of information about estimates of physical activity from surveillance systems. ${ }^{85}$ For example, future communication efforts can provide explanations for the differences in prevalence estimates across measures by incorporating this information into widely accessed materials, such as codebooks and manuals for national data sets. ${ }^{61,85}$

\section{Conclusion}

Over the past 20 years, national and state surveillance systems have used a variety of measures to monitor physical activity and sedentary behaviors among children, adolescents, and adults, resulting in a wide array of available data. The evolving landscape of physical activity surveillance in the United States has resulted in both broad challenges and emerging opportunities, including balancing content and survey space; providing data at the national, state, and local level; adapting traditional physical activity measures and survey designs; and addressing variation across surveillance systems.

\section{Acknowledgments}

The findings and conclusions in this report are those of the authors and do not necessarily represent the official position of the CDC.

\section{References}

1. Thacker SB, Berkelman RL. Public health surveillance in the United States. Epidemiol Rev. 1988;10(1):164-190. PubMed ID: 3066626 doi:10.1093/oxfordjournals.epirev.a036021

2. Physical Activity Guidelines Advisory Committee. Physical Activity Guidelines Advisory Committee Scientific Report, 2008. Washington, DC: U.S. Department of Health and Human Services; 2008.

3. Physical Activity Guidelines Advisory Committee. 2018 Physical Activity Guidelines Advisory Committee Scientific Report. Washington, DC: U.S. Department of Health and Human Services; 2018.

4. Ainsworth BE, Macera CA. Physical Activity and Public Health Practice. Boca Raton, FL: Taylor \& Francis; 2012.

5. Morris JN, Heady JA, Raffle PAB, Roberts CG, Parks JW. Coronary heart-disease and physical activity of work. Lancet. 1953;262(6795): 1053-1057. PubMed ID: 13110049 doi:10.1016/S0140-6736(53) 90665-5

6. Paffenbarger RS, Wolf PA, Notkin J, Thorne MC. Chronic disease in former college students: I. Early precursors of fatal coronary heart disease. Am J Epidemiol. 1966;83(2):314-328. PubMed ID: 5930778 doi:10.1093/oxfordjournals.aje.a120587

7. American College of Sports Medicine position statement on the recommended quantity and quality of exercise for developing and maintaining fitness in healthy adults. Med Sci Sports. 1978;10(3):vii-x. PubMed ID: 723501

8. Pate RR, Pratt M, Blair SN, et al. Physical activity and public health: a recommendation from the Centers for Disease Control and Prevention and the American College of Sports Medicine. JAMA. 1995; 273(5):402-407. PubMed ID: 7823386 doi:10.1001/jama.1995. 03520290054029

9. US Department of Health and Human Services. 2008 Physical Activity Guidelines for Americans. Washington, DC: U.S. Department of Health and Human Services; 2008.

10. US Department of Health and Human Services. Physical Activity Guidelines for Americans. 2nd ed. Washington, DC: U.S. Department of Health and Human Services; 2018.

11. US Department of Health and Human Services. Physical activity and health: a report of the Surgeon General. Atlanta, Georgia: US Department of Health and Human Services, Public Health Service, CDC, National Center for Chronic Disease Prevention and Health Promotion; 1996.

12. Haskell WL, Lee IM, Pate RR, et al. Physical activity and public health: updated recommendation for adults from the American College of Sports Medicine and the American Heart Association. Med Sci Sports Exerc. 2007;39(8):1423-1434. PubMed ID: 17762377 doi:10.1249/mss.0b013e3180616b27

13. Nelson ME, Rejeski WJ, Blair SN, et al. Physical activity and public health in older adults: recommendation from the American College of Sports Medicine and the American Heart Association. Med Sci Sports Exerc. 2007;39(8):1435-1445. PubMed ID: 17762378 doi:10.1249/ mss.0b013e3180616aa2

14. US Department of Health and Human Services. Healthy People 2030. 2020. https://health.gov/healthypeople. Accessed October 26, 2020.

15. Troiano RP, Macera CA, Ballard-Barbash R. Be physically active each day. How can we know? J Nutr. 2001;131(2):451S-460S. doi:10.1093/jn/131.2.451S

16. Centers for Disease Control and Prevention. 2020 National Health Interview Survey (NHIS) Questionnaire. April 5, 2021. https://ftp. cdc.gov/pub/Health_Statistics/NCHS/Survey_Questionnaires/NHIS/ 2020/EnglishQuest.pdf. Accessed May 5, 2021.

17. Troiano RP, Berrigan D, Dodd KW, Masse LC, Tilert T, McDowell M. Physical activity in the United States measured by accelerometer. Med Sci Sports Exerc. 2008;40(1):181-188. PubMed ID: 18091006 doi:10.1249/mss.0b013e31815a51b3

18. Centers for Disease Control and Prevention. National Health and Nutrition Examination Survey (NHANES). August 14, 2020. https:// www.cdc.gov/nchs/nhanes/. Accessed August 19, 2020.

19. Czajka JL, Beyler A. Declining Response Rates in Federal Surveys: Trends and Implications. Vol. 1. Washington, DC: Mathematica Policy Research. 2016. https://aspe.hhs.gov/system/files/ pdf/255531/Decliningresponserates.pdf. Accessed November 2, 2020.

20. Lee K, Sener IN. Emerging data for pedestrian and bicycle monitoring: sources and applications. Transp Res Interdiscip Perspect. 2020;4:100095.

21. Centers for Disease Control and Prevention. About the Behavioral Risk Factor Surveillance System (BRFSS). 2014. https://www.cdc. gov/brfss/about/about_brfss.htm. Accessed June 23, 2021.

22. National Center for Health Statistics. National Health and Nutrition Examination Survey: History. 2015. https://www.cdc.gov/nchs/ nhanes/history.htm. Accessed June 23, 2021. 
23. Centers for Disease Control and Prevention. About the National Health Interview Survey. 2020. https://www.cdc.gov/nchs/nhis/ about_nhis.htm. Accessed June 23, 2021.

24. US Census Bureau. American Community Survey Information Guide. 2017. https://www.census.gov/content/dam/Census/programssurveys/acs/about/ACS_Information_Guide.pdf. Accessed June 23, 2021.

25. US Census Bureau. Understanding and Using American Community Survey Data: What All Data Users Need to Know. 2018. https:// www.census.gov/content/dam/Census/library/publications/2018/ acs/acs_general_handbook_2018.pdf. Accessed October 28, 2020.

26. US Census Bureau. American Time Use Survey User's Guide: Understanding ATUS 2003 to 2019. 2020. https://www.bls.gov/ tus/atususersguide.pdf. Accessed October 28, 2020.

27. Centers for Disease Control and Prevention. Behavioral Risk Factor Surveillance System (BRFSS). November 5, 2019. https://www.cdc. gov/BRFSS/. Accessed August 19, 2020.

28. Centers for Disease Control and Prevention. Methodologic changes in the Behavioral Risk Factor Surveillance System in 2011 and potential effects on prevalence estimates. MMWR Morb Mortal Wkly Rep. 2012;61(22):410-413.

29. Centers for Disease Control and Prevention. BRFSS 2011 Survey Data and Documentation. 2013. https://www.cdc.gov/brfss/annual_ data/annual_2011.htm. Accessed March 15, 2021.

30. National Center for Health Statistics. National Health and Nutrition Examination Survey, 2015-2018: Sample Design and Estimation Procedures. 2020. https://www.cdc.gov/nchs/data/series/sr_02/sr02184-508.pdf. Accessed March 15, 2021.

31. Centers for Disease Control and Prevention. National Health Interview Survey (NHIS). August 18, 2020. https://www.cdc.gov/nchs/ nhis/. Accessed August 19, 2020.

32. Centers for Disease Control and Prevention. 2019 National Health Interview Survey (NHIS) Survey Description. 2020. https://ftp.cdc. gov/pub/Health_Statistics/NCHS/Dataset_Documentation/NHIS/2019/ srvydesc-508.pdf. Accessed May 7, 2021.

33. The Child \& Adolescent Health Measurement Initiative (CAHMI). The National Survey of Children's Health. Data Resource Center for Child \& Adolescent Health (DRC). https://www.childhealthdata.org/ learn-about-the-nsch/NSCH. Accessed August 19, 2020.

34. Centers for Disease Control and Prevention. Youth Risk Behavior Surveillance System (YRBSS). August 20, 2020. https://www.cdc. gov/healthyyouth/data/yrbs/. Accessed August 20, 2020.

35. Black LI, Clarke TC, Barnes PM, Stussman BJ, Nahin RL. Use of complementary health approaches among children aged 4-17 years in the United States: National Health Interview Survey, 2007-2012. Natl Health Stat Report. 2015;(78):1-19.

36. Black LI, Barnes PM, Clarke TC, Stussman BJ, Nahin RL. Use of yoga, meditation, and chiropractors among U.S. children aged 4-17 years. NCHS Data Brief. 2018;(324):1-8.

37. Moore LV, Harris CD, Carlson SA, Kruger J, Fulton JE. Trends in no leisure-time physical activity-United States, 1988-2010. Res $Q$ Exerc Sport. 2012;83(4):587-591. PubMed ID: 23367822 doi:10. 1080/02701367.2012.10599884

38. National Center for Health Statistics. Adult Physical Activity Information. January 3, 2017. https://www.cdc.gov/nchs/nhis/physical_ activity.htm. Accessed May 7, 2021.

39. Tudor-Locke C, Washington TL, Ainsworth BE, Troiano RP. Linking the American Time Use Survey (ATUS) and the compendium of physical activities: methods and rationale. J Phys Act Health. 2009; 6(3):347-353. PubMed ID: 19564664 doi:10.1123/jpah.6.3.347

40. Tudor-Locke C, Leonardi C, Johnson WD, Katzmarzyk PT. Time spent in physical activity and sedentary behaviors on the working day: the American Time Use Survey. J Occup Environ Med. 2011;53(12):1382-1387. PubMed ID: 22104979 doi:10.1097/ JOM.0b013e31823c1402

41. Whitfield GP, Paul P, Wendel AM. Active transportation surveillance -United States, 1999-2012. MMWR Surveill Summ. 2015;64(7):117. PubMed ID: 26313567 doi:10.15585/mmwr.ss6407a1

42. McGuckin N, Fucci A. Summary of Travel Trends: 2017 National Household Travel Survey. 2018. https://nhts.ornl.gov/assets/2017_ nhts_summary_travel_trends.pdf. Accessed October 28, 2020.

43. Watson KB, Carlson SA, Carroll DD, Fulton JE. Comparison of accelerometer cut points to estimate physical activity in U.S. adults. $J$ Sports Sci. 2013;32(7):660-669. PubMed ID: 24188163 doi:10. 1080/02640414.2013.847278

44. Montoye AHK, Clevenger KA, Pfeiffer KA, et al. Development of cut-points for determining activity intensity from a wrist-worn ActiGraph accelerometer in free-living adults. J Sports Sci. 2020;38(22):2569-2578. PubMed ID: 32677510 doi:10.1080/ 02640414.2020 .1794244

45. National Center for Health Statistics. Selected Estimates Based on Data from the National Health Interview Survey. February 11, 2021. https://www.cdc.gov/nchs/nhis/erkeyindicators.htm. Accessed May 7, 2021.

46. Centers for Disease Control and Prevention. NHIS Early Release Program. https://www.cdc.gov/nchs/nhis/releases.htm. Accessed November 2, 2020.

47. Centers for Disease Control and Prevention. YRBSS Reports, Fact Sheets, and Publications. 2020. https://www.cdc.gov/healthyyouth/ data/yrbs/reports_factsheet_publications.htm. Accessed November 4, 2020.

48. United States Census Bureau. Explore Census Data. https://data. census.gov/. Accessed November 2, 2020.

49. United States Department of Transportation. Explore NHTS Data. https://nhts.ornl.gov/. Accessed November 2, 2020.

50. Centers for Disease Control and Prevention. BRFSS Prevalence Data \& Data Analysis Tools. 2020. https://www.cdc.gov/brfss/data_tools. htm. Accessed November 4, 2020.

51. Data Resource Center for Child \& Adolescent Health. National Survey of Children's Health Interactive Data Query (2016-Present). https://www.childhealthdata.org/browse/survey. Accessed November 4, 2020.

52. The Global Observatory for Physical Activity. 1st Physical Activity Almanac: The Global Observatory for Physcial Activity-GoPA! 2016. https://indd.adobe.com/view/f8d2c921-4daf-4c96-9eafb8fb2c4de615. Accessed June 23, 2021.

53. US Department of Health and Human Services. Healthy People 2020. 2010. https://www.healthypeople.gov/2020. Accessed October 28, 2020.

54. Centers for Disease Control and Prevention. Nutrition, Physical Activity, and Obesity: Data, Trends and Maps. July 8, 2020. https://www.cdc.gov/nccdphp/dnpao/data-trends-maps/index.html. Accessed August 19, 2020.

55. Du Y, Liu B, Sun Y, Snetselaar LG, Wallace RB, Bao W. Trends in adherence to the physical activity guidelines for Americans for aerobic activity and time spent on sedentary behavior among US adults, 2007 to 2016. JAMA Netw Open. 2019;2(7):e197597. PubMed ID: 31348504 doi:10.1001/jamanetworkopen.2019.7597

56. Brawner CA, Churilla JR, Keteyian SJ. Prevalence of physical activity is lower among individuals with chronic disease. Med Sci Sports Exerc. 2016;48(6):1062-1067. PubMed ID: 26741117 doi:10.1249/MSS.0000000000000861

57. Steeves JA, Murphy RA, Crainiceanu CM, Zipunnikov V, Van Domelen DR, Harris TB. Daily patterns of physical activity by 
type 2 diabetes definition: comparing diabetes, prediabetes, and participants with normal glucose levels in NHANES 2003-2006. Prev Med Rep. 2015;2:152-157. PubMed ID: 25909051 doi:10. 1016/j.pmedr.2015.02.007

58. Murphy LB, Hootman JM, Boring MA, et al. Leisure time physical activity among U.S. adults with arthritis, 2008-2015. Am J Prev Med. 2017;53(3):345-354. PubMed ID: 28601405 doi:10.1016/j.amepre. 2017.03.017

59. Zhao G, Ford ES, Li C, Mokdad AH. Compliance with physical activity recommendations in US adults with diabetes. Diabet Med. 2008;25(2):221-227. PubMed ID: 18201213 doi:10.1111/j.14645491.2007.02332.x

60. Omura JD, Brown DR, McGuire LC, Taylor CA, Fulton JE, Carlson SA. Cross-sectional association between physical activity level and subjective cognitive decline among US adults aged $\geq 45$ years, 2015. Prev Med. 2020;141:106279. PubMed ID: 33035548 doi:10.1016/j. ypmed.2020.106279

61. Carlson SA, Densmore D, Fulton JE, Yore MM, Kohl HW III. Differences in physical activity prevalence and trends from 3 US surveillance systems: NHIS, NHANES, and BRFSS. $J$ Phys Act Health. 2009;6(suppl):S18-S27. doi:10.1123/jpah.6.s1.s18

62. Whitfield GP, Carlson SA, Ussery EN, Fulton JE, Galuska DA, Petersen R. Trends in meeting physical activity guidelines among urban and rural dwelling adults-United States, 2008-2017. MMWR Morb Mortal Wkly Rep. 2019;68(23):513-518. PubMed ID: 31194722 doi:10.15585/mmwr.mm6823a1

63. Omura JD, Ussery EN, Loustalot F, Fulton JE, Carlson SA. Walking as an opportunity for cardiovascular disease prevention. Prev Chronic Dis. 2019;16:E66. PubMed ID: 31146804 doi:10.5888/ pcd16.180690

64. Ussery EN, Carlson SA, Whitfield GP, Watson KB, Berrigan D, Fulton JE. Walking for transportation or leisure among U.S. women and men-National Health Interview Survey, 2005-2015. MMWR Morb Mortal Wkly Rep. 2017;66(25):657-662. PubMed ID: 28662018 doi:10.15585/mmwr.mm6625a1

65. Ussery EN, Carlson SA, Whitfield GP, Watson KB, Berrigan D, Fulton JE. Transportation and leisure walking among U.S. adults: trends in reported prevalence and volume, National Health Interview Survey 2005-2015. Am J Prev Med. 2018;55(4):533-540. PubMed ID: 30139708 doi:10.1016/j.amepre.2018.05.027

66. Whitfield GP, Carlson SA, Ussery EN, Watson KB, Berrigan D, Fulton JE. National-level environmental perceptions and walking among urban and rural residents: informing surveillance of walkability. Prev Med. 2019;123:101-108. PubMed ID: 30878571 doi:10.1016/j.ypmed.2019.03.019

67. Whitfield GP, Carlson SA, Ussery EN, et al. Racial and ethnic differences in perceived safety barriers to walking, United States National Health Interview Survey-2015. Prev Med. 2018;114:5763. PubMed ID: 29894716 doi:10.1016/j.ypmed.2018.06.003

68. Carlson SA, Whitfield GP, Peterson EL, et al. Geographic and urbanrural differences in walking for leisure and transportation. Am J Prev Med. 2018;55(6):887-895. PubMed ID: 30344032 doi:10.1016/j. amepre.2018.07.008

69. Watson KB, Whitfield GP, Thomas JV, Berrigan D, Fulton JE, Carlson SA. Associations between the National Walkability Index and walking among US adults-National Health Interview Survey, 2015. Prev Med. 2020;137:106122. PubMed ID: 32389677 doi:10. 1016/j.ypmed.2020.106122

70. Ussery EN, Fulton JE, Galuska DA, Katzmarzyk PT, Carlson SA. Joint prevalence of sitting time and leisure-time physical activity among US adults, 2015-2016. JAMA. 2018;320(19):2036-2038. PubMed ID: 30458482 doi:10.1001/jama.2018.17797
71. Yang L, Cao C, Kantor ED, et al. Trends in sedentary behavior among the US population, 2001-2016. JAMA. 2019;321(16):15871597. PubMed ID: 31012934 doi:10.1001/jama.2019.3636

72. Ussery EN, Whitfield GP, Fulton JE, et al. Trends in self-reported sitting time by physical activity levels among US adults, NHANES 2007/2008-2017/2018. J Phys Act Health. 2021;18(Suppl):S74S83. doi:10.1123/jpah.2021-0221

73. Centers for Disease Control and Prevention. Youth Online. https://nccd. cdc.gov/youthonline/App/Default.aspx. Accessed October 28, 2020.

74. Matthews CE, Chen KY, Freedson PS, et al. Amount of time spent in sedentary behaviors in the United States, 2003-2004. Am J Epidemiol. 2008;167(7):875-881. PubMed ID: 18303006 doi:10.1093/aje/kwm390

75. Matthews CE, Keadle SK, Troiano RP, et al. Accelerometer-measured dose-response for physical activity, sedentary time, and mortality in US adults. Am J Clin Nutr. 2016;104(5):1424-1432. PubMed ID: 27707702 doi:10.3945/ajcn.116.135129

76. Tudor-Locke C, Camhi SM, Troiano RP. A catalog of rules, variables, and definitions applied to accelerometer data in the National Health and Nutrition Examination Survey, 2003-2006. Prev Chronic Dis. 2012;9:E113. PubMed ID: 22698174 doi:10.5888/pcd9.110332

77. Gahche J, Fakhouri T, Carroll DD, Burt VL, Wang CY, Fulton JE. Cardiorespiratory Fitness Levels Among U.S. Youth Aged 12-15 Years: United States, 1999-2004 and 2012. NCHS Data Brief,no 153. Hyattsville, MD: National Center for Health Statistics. 2014.

78. Ervin RB, Wang CY, Fryar CD, Miller IM, Ogden CL. Measures of Muscular Strength in U.S. Children and Adolescents, 2012. NCHS Data Brief, no 139. Hyattsville, MD: National Center for Health Statistics. 2013.

79. Wang CY, Haskell WL, Farrell SW, et al. Cardiorespiratory fitness levels among US adults 20-49 years of age: findings from the 19992004 National Health and Nutrition Examination Survey. Am J Epidemiol. 2010;171(4):426-435. PubMed ID: 20080809 doi:10. 1093/aje/kwp412

80. Ross JG, Pate RR, Delpy LA, Cold RS, Svilar M. New health-related fitness norms. J Phys Educ Recreat Dance. 1987;58(9):66-70. doi:10.1080/07303084.1987.10604377

81. Pate RR. A new definition of youth fitness. Phys Sportsmed. 1983;11(4):77-83. doi:10.1080/00913847.1983.11708509

82. Pate RR, Ross JG. Factors associated with health-related fitness. $J$ Phys Educ Recreat Dance. 1987;58(9):93-97. doi:10.1080/ 07303084.1987.10604382

83. Pate RR, Ross JG, Baumgartner TA, Sparks RE. The modified pullup test. J Phys Educ Recreat Dance. 1987;58(9):71-73. doi:10.1080/ 07303084.1987.10604378

84. Bai Y, Chen S, Laurson KR, Kim Y, Saint-Maurice PF, Welk GJ. The associations of youth physical activity and screen time with fatness and fitness: the 2012 NHANES National Youth Fitness Survey. PLoS One. 2016;11(1):e0148038. PubMed ID: 26820144 doi:10.1371/ journal.pone.0148038

85. Fulton JE, Carlson SA, Ainsworth BE, et al. Strategic priorities for physical activity surveillance in the United States. Med Sci Sports Exerc. 2016;48(10):2057-2069. PubMed ID: 27187094 doi:10. 1249/MSS.0000000000000989

86. Project Enhance. Enhance®Fitness. https://projectenhance.org/ enhancefitness/. Accessed February 19, 2021.

87. Centers for Disease Control and Prevention. National Youth Physical Activity and Nutrition Study. https://www.cdc.gov/healthyyouth/ data/yrbs/nypans.htm. Accessed November 4, 2020.

88. Centers for Disease Control and Prevention. National Health and Nutrition Examination Survey: National Youth Fitness Survey. 2020. https://www.cdc.gov/nchs/nnyfs/index.htm. Accessed November 4, 2020. 
89. Zhang X, Holt JB, Yun S, Lu H, Greenlund KJ, Croft JB. Validation of multilevel regression and poststratification methodology for small area estimation of health indicators from the Behavioral Risk Factor Surveillance System. Am J Epidemiol. 2015;182(2):127-137. PubMed ID: 25957312 doi:10.1093/aje/kwv002

90. Datta GS. Model-based approach to small area estimation. In: Pfeffermann D, Rao CR, ed. Handbook of Statistics: Sample Surveys: Inference and Analysis. Elsevier, Amsterdam: The Netherlands; 2009:251-288.

91. Rao JNK, Molina I. Small Area Estimation. Hoboken, NJ: John Wiley \& Sons Inc; 2015.

92. Centers for Disease Control and Prevention. PLACES. 2020. https:// www.cdc.gov/places/index.html. Accessed February 19, 2021.

93. Sallis JF, Saelens BE. Assessment of physical activity by self-report: status, limitations, and future directions. Res Q Exerc Sport. 2000;71(suppl):1-14. doi:10.1080/02701367.2000.11082780

94. Bowles HR. Measurement of active and sedentary behaviors: closing the gaps in self-report methods. J Phys Act Health. 2012;9(suppl): S1-S4. doi:10.1123/jpah.9.s1.s1

95. Masse LC, de Niet JE. Sources of validity evidence needed with selfreport measures of physical activity. J Phys Act Health. 2012;9(suppl 1):S44-S55. doi:10.1123/jpah.9.s1.s44

96. Troiano RP, Pettee Gabriel KK, Welk GJ, Owen N, Sternfeld B. Reported physical activity and sedentary behavior: why do you ask? J Phys Act Health. 2012;9(suppl):S68-S75. doi:10.1123/jpah.9.s1. s68

97. Ainsworth BE, Caspersen CJ, Matthews CE, Masse LC, Baranowski $\mathrm{T}, \mathrm{Zhu} \mathrm{W}$. Recommendations to improve the accuracy of estimates of physical activity derived from self report. J Phys Act Health. 2012;9(suppl):S76-S84. doi:10.1123/jpah.9.s1.s76

98. AAP Council on Communications and Media, Strasburger VC. Children, adolescents, obesity, and the media. Pediatrics. 2011;128(1):201-208. doi:10.1542/peds.2011-1066

99. Verloigne M, Van Lippevelde W, Maes L, et al. Self-reported TV and computer time do not represent accelerometer-derived total sedentary time in 10 to 12-year-olds. Eur J Public Health. 2013;23(1):30-32. PubMed ID: 22544913 doi:10.1093/eurpub/cks047

100. Rideout V, Robb MB. The Common Sense Census: Media Use by Tweens and Teens, 2019. San Francisco, CA: Common Sense Media; 2019.

101. Herrick KA, Fakhouri TH, Carlson SA, Fulton JE. TV watching and computer use in U.S. youth aged 12-15, 2012. NCHS Data Brief. 2014;(157):1-8.

102. Prince SA, Cardilli L, Reed JL, et al. A comparison of self-reported and device measured sedentary behaviour in adults: a systematic review and meta-analysis. Int J Behav Nutr Phys Act. 2020;17(1):31. PubMed ID: 32131845 doi:10.1186/s12966-020-00938-3

103. Troiano RP, McClain JJ, Brychta RJ, Chen KY. Evolution of accelerometer methods for physical activity research. Br J Sports
Med. 2014;48(13):1019-1023. PubMed ID: 24782483 doi:10.1136/ bjsports-2014-093546

104. Centers for Disease Control and Prevention. 1998 National Health Interview Survey (NHIS) Public Use Data Release. 2000. https://ftp. cdc.gov/pub/Health_Statistics/NCHS/Dataset_Documentation/NHIS/ 1998/srvydesc.pdf. Accessed October 28, 2020.

105. Centers for Disease Control and Prevention. 2018 National Health Interview Survey (NHIS) Public Use Data Release. 2019. https://ftp. cdc.gov/pub/Health_Statistics/NCHS/Dataset_Documentation/NHIS/ 2018/srvydesc.pdf. Accessed October 28, 2020.

106. Centers for Disease Control and Prevention. 1998 BRFSS Summary Quality Control Report. 1998. https://www.cdc.gov/brfss/annual_ data/1998/pdf/1998SummaryDataQualityReport.pdf. Accessed October 28, 2020.

107. Centers for Disease Control and Prevention. Behavioral Risk Factor Surveillance System 2018 Summary Quality Control Report. 2019. https://www.cdc.gov/brfss/annual_data/2018/pdf/2018-sdqr-508.pdf. Accessed October 28, 2020.

108. Rolle-Lake L, Robbins E. Behavioral Risk Factor Surveillance System (BRFSS). StatPearls [Internet]. StatPearls Publishing LLC; 2020.

109. National Academies of Sciences, Engineering, and Medicine. Innovations in Federal Statistics: Combining Data Sources While Protecting Privacy. Washington, DC: The National Academies Press; 2017.

110. Omura JD, Carlson SA, Paul P, Watson KB, Fulton JE. National physical activity surveillance: Users of wearable activity monitors as a potential data source. Prev Med Rep. 2017;5:124-126. PubMed ID: 28101443 doi:10.1016/j.pmedr.2016.10.014

111. Strain T, Wijndaele K, Brage S. Physical activity surveillance through smartphone apps and wearable trackers: examining the UK potential for nationally representative sampling. JMIR Mhealth Uhealth. 2019;7(1):e11898. PubMed ID: 30694198 doi:10.2196/11898

112. Ernsting C, Dombrowski SU, Oedekoven M, et al. Using smartphones and health apps to change and manage health behaviors: a population-based survey. J Med Internet Res. 2017;19(4):e101. PubMed ID: 28381394 doi:10.2196/jmir.6838

113. National Academies of Sciences, Engineering, and Medicine. Implementing Strategies to Enhance Public Health Surveillance of Physical Activity in the United States. Washington, DC: The National Academies Press; 2019.

114. Hyde ET, Omura JD, Fulton JE, Weldy A, Carlson SA. Physical activity surveillance using wearable activity monitors: are US adults willing to share their data? Am J Health Promot. 2020;34(6):672676. PubMed ID: 31957481 doi:10.1177/0890117119900587

115. Keadle SK, McKinnon R, Graubard BI, Troiano RP. Prevalence and trends in physical activity among older adults in the United States: a comparison across three national surveys. Prev Med. 2016;89:37-43. PubMed ID: 27196146 doi:10.1016/j.ypmed.2016.05.009 